\title{
Zirconia as a Support for Catalysts
}

\section{Evolution of the Texture and Structure on Calcination in Air}

\author{
P.D.L. MERCERA*, J.G. VAN OMMEN, E.B.M. DOESBURG, A.J. BURGGRAAF, \\ and J.R.H. ROSS \\ Laboratory of Inorganic Chemistry, Materials Science and Catalysis, Faculty of Chemicai \\ Technology, University of Twente, P.O. Box 217, 7500AE Enschede \\ (The Netherlands)
}

(Received 27 June 1989, revised manuscript received 1 September 1989)

\begin{abstract}
Zirconia samples, prepared by precipitation from a solution of zirconyl chloride at a constant $\mathrm{pH}$ of 10 , were calcined in flowing air at temperatures up to $850^{\circ} \mathrm{C}$ in order to study the development and stability of the porous texture in conjunction with the development of the structure of the resulting materials as a function of calcination temperature. The gel precipitation technique employed yields a high surface area zirconia $\left(S_{\mathrm{BET}}\right.$ of $111 \mathrm{~m}^{2} \mathrm{~g}^{-1}$ after calcination at $\left.450^{2} \mathrm{C}\right)$ with a well-developed mesoporous texture. The porous texture is, however, unstable under the experimental conditions employed, the initial high specific surface area being lost quite rapidly with increase in calcination temperature; calcination at $850^{\circ} \mathrm{C}$ brings about a reduction of the (BET) specific surface area by approximately $97 \%$. Two process were identified as being responsible for the changes in pore structure and surface area: (i) crystallite growth and an accompanying phase transformation; and (ii) inter-crystallite sintering (neck-formation and growth); both these phenomena probably occur via a mechanism of surface diffusion. The inter-crystallite sintering process becomes more pronounced at higher calcination temperatures.
\end{abstract}

\section{INTRODUCTION}

Zirconia is attracting considerable interest on account of its potential use as a catalyst support. To give an impression of this new interest, a recently performed CAS-online search by us showed that more than $70 \%$ of the relevant publications date from the last five years; some examples of promising zirconia-supported catalytic systems will be outlined in the next paragraph.

Zirconia-supported copper catalysts seem to be of particular interest because, like the $\mathrm{CuO} / \mathrm{ZnO} / \mathrm{Al}_{2} \mathrm{O}_{3}$ system, they are active and selective for the synthesis of methanol from $\mathrm{CO} / \mathrm{H}_{2}, \mathrm{CO}_{2} / \mathrm{H}_{2}$ and $\mathrm{CO} / \mathrm{CO}_{2} / \mathrm{H}_{2}$ mixtures [1-3]. Copper supported on zirconia has in fact been found to be superior to copper 
supported on other oxides such as $\mathrm{ZnO}, \mathrm{Al}_{2} \mathrm{O}_{3}, \mathrm{SiO}_{2}$ and $\mathrm{TiO}_{2}$ [2]. In the hydrogenation of $\mathrm{CO}$ and $\mathrm{CO}_{2}$ to hydrocarbons, rhodium supported on $\mathrm{ZrO}_{2}$ has been found to exhibit a higher activity than $\mathrm{Rh}$ supported on the 'classical supports' $\left(\mathrm{Al}_{2} \mathrm{O}_{3}\right.$ and $\left.\mathrm{SiO}_{2}\right)$ and $\mathrm{MgO}$ [4-6]. Whereas nickel supported on the classical supports gives methanation of $\mathrm{CO}+\mathrm{H}_{2}$ mixtures, zirconia-supported nickel has a selectivity which is shifted towards higher hydrocarbons, there being a high proportion of olefins in the product $[7,8]$. The sensitivity of $\mathrm{Ni}$ / $\mathrm{ZrO}_{2}$ to, for example, $\mathrm{H}_{2} \mathrm{~S}$ is also less than that of other catalysts such as $\mathrm{Ni} / \mathrm{Al}_{2} \mathrm{O}_{3}[9]$.

It has become well established that the performance of a heterogeneous catalyst not only depends on the intrinsic catalytic activity of the components but also on its texture and stability. One of the most important factors in controlling the texture and strength of a catalyst involves the correct choice of a support and the preparation of the support in the appropriate form [10,11]. Extensive studies have been made of the effect of temperature on the development of the porous texture $[12-20]$ or structure $[12,13,21-26]$ in samples of zirconia prepared either by precipitation from (aqueous) solutions or by thermal decomposition of zirconium salts. The majority of the textural studies have, however, been confined to low calcination temperatures $\left(\leq 500^{\circ} \mathrm{C}\right)$. More important, to the best of our knowledge only a few investigators have studied the development of the porous texture on calcination concurrently with the development of the structure. The studies carried out by Rijnten [12], Crucean and Rand [13] and by Tulier et al. [27] have shown that, besides sintering phenomena, the phase (s) formed on heat treatment, the extent of crystallite growth, and the extent and rate of phase transformation are also all factors of importance in understanding (and eventually in improving) the textural stability of zirconia supports.

The work reported here forms part of a systematic study of the development and characterization of high surface area zirconia with a well-defined mesoporous texture which is stable under thermal and hydrothermal conditions. The present investigation sets out to study the development of the porous texture and structure of hydrous zirconia on calcination in air at various temperatures up to $850^{\circ} \mathrm{C}$, to identify the mechanisms which influence the resulting surface area and porosity, and to estimate their relative importance.

\section{EXPERIMENTAL}

\section{Sample preparation}

Samples of hydrous zirconia were made by precipitation at room temperature at a constant $\mathrm{pH}$ of 10.0. A solution of zirconyl chloride (Merck, Pro Analysis, $0.4 \mathrm{M}$ ) was added dropwise, at a rate of $10.3 \mathrm{~cm}^{3} \mathrm{~min}^{-1}$, concurrently with a solution of ammonia (Merck, Pro Analysis, 6.7 M) to doubly distilled 
water (the $\mathrm{pH}$ of which had previously been adjusted to 10.0 with ammonia). The $\mathrm{pH}$ of precipitation was controlled to within $0.05 \mathrm{pH}$ units by using an Ingold Xerolyt electrode to monitor the $\mathrm{pH}$ continuously. $\mathrm{A} \mathrm{pH}$ of 10 was chosen because work from our own laboratory as well as from other investigators [12-14] has shown that (i) the degree of mesoporosity (ii) the specific surface area, and (iii) the total pore volume of the resultant hydrous zirconia all increase with increasing $\mathrm{pH}$ of precipitation.

The precipitate formed as described above was aged in the mother liquor for $65 \mathrm{~h}$, after which it was filtered and then washed by repeated cycles of redispersion in doubly distilled water and filtration. Washing was continued until a negative test for chloride ions was obtained $\left(\mathrm{AgNO}_{3}\right.$-test, $3 \mathrm{M} \mathrm{AgNO}_{3}$ solution). Both the precipitation and washing steps were carried out in a baffled vessel reactor of the type described by Van de Graaf et al. [28]; the reactor was equipped with a dispersion turbine during precipitation and with a high energy disc turbine during washing. After the last washing/filtration step, the hydrous zirconia was dried in air at $110^{\circ} \mathrm{C}$ for $20 \mathrm{~h}$ to yield large particles of a glassy gel. Moistening of this material with doubly distilled water caused the product to shatter into small gel particles of ca. $1 \mathrm{~mm}$. This material was dried for another $20 \mathrm{~h}$ in air at $110^{\circ} \mathrm{C}$, and was then ground to particle sizes of less than $100 \mu \mathrm{m}$ using an agate pestle and mortar.

\section{Calcination procedure}

The samples were studied both in the freshly prepared state and after calcination. Calcination was carried out in a flow of air $\left(150 \mathrm{~cm}^{3} \mathrm{~min}^{-1}\right)$ in a Stanton Redcroft tube furnace at various temperatures up to $850^{\circ} \mathrm{C}$. The temperature was increased at a rate of $3^{\circ} \mathrm{C} \mathrm{min}^{-1}$ to the final temperature; this was maintained for $15 \mathrm{~h}$ before cooling to $200^{\circ} \mathrm{C}$ at a rate of $5^{\circ} \mathrm{C} \mathrm{min}-1$ and then cooling rapidly to room temperature.

\section{Chemical analysis}

The purity of the dried precipitate was qualitatively determined by means of X-ray fluorescence analysis (XRF). The bulk chloride content, which serves as a quality control parameter, was also quantitatively determined by an argentometric method. For this purpose, about $0.5 \mathrm{~g}$ of the sample in question was dissolved in $1 \mathrm{~cm}^{3}$ of a $40 \% \mathrm{HF}$ solution. After dilution to a volume of 11 $\mathrm{cm}^{3}$ and addition of a few drops of phenolphthalein, concentrated ammonia was added until colour change occurred. A volume of $40 \mathrm{~cm}^{3}$ of $100 \%$ acetic acid was then added and a titration was performed using a $0.01 M$ solution of $\mathrm{AgNO}_{3}$. The titration was carried out using a Metrohm 636 titroprocessor employing an $\mathrm{Ag} / \mathrm{Ag}_{2} \mathrm{SO}_{4}$ electrode. 


\section{Thermal analysis}

The thermogravimetric ( $T G$ ) studies reported here were performed in flowing air ( $35 \mathrm{~cm}^{3} \mathrm{~min}^{-1}$ ) with a DuPont Thermal Analyzer (951 TG system, 990 control unit). The sample size ranged from 9.0 to $10.0 \mathrm{mg}$ and a programming rate of $10^{\circ} \mathrm{C} \mathrm{min}^{-1}$ was used in all cases. Prior to each experiment, the sample to be examined was maintained isothermally at $100^{\circ} \mathrm{C}$ in order to remove any physically adsorbed water. The weight changes were measured to an accuracy of $0.01 \mathrm{mg}$.

Differential scanning calorimetry (DSC) studies were carried out using a Stanton Redcroft DSC apparatus (DSC 1500 system) together with a Stanton Redcroft high sensitivity DSC cell. The experiments were all performed by raising the temperature linearly at a rate of $10^{\circ} \mathrm{C} \mathrm{min}^{-1}$ in a stream of air (35 $\mathrm{cm}^{3} \mathrm{~min}^{-1}$ ). A sample size of $11.0 \pm 0.5 \mathrm{mg}$ was employed in all the experiments. A sample of $\alpha$-alumina $(11.0 \pm 0.5 \mathrm{mg})$ was used as reference.

\section{Nitrogen physisorption}

Full nitrogen adsorption/desorption isotherms at $-196^{\circ} \mathrm{C}$ were obtained using a Micromeritics ASAP 2400 system. The calcined samples were first outgassed for 5 to $6 \mathrm{~h}$ at $300^{\circ} \mathrm{C}$ while the uncalcined sample was outgassed at $100^{\circ} \mathrm{C}$ until constant residual pressure had been achieved. Analysis of the isotherms was carried out following to a large extent the methodology proposed by Broekhoff [29] as further generalized by Lecloux [30]; the corrections suggested by Broekhoff were not used in the calculation of the pore size distributions.

\section{$X$-ray powder diffraction measurement and analysis}

X-ray diffraction patterns were recorded using a Philips PW 1710 diffractometer with $\mathrm{Cu} \mathrm{K} \alpha$ radiation. Both the continuous and the step-scan techniques were used, the latter being employed for quantitative analysis. The step scans were taken over the range of $2 \theta$ from 26 to $33^{\circ}$ in steps of $0.015^{\circ}(2 \theta)$, the intensity data for each point being collected for $10 \mathrm{~s}$. In order to further improve counting statistics, rotation about the normal axis was used.

The diffraction peaks measured in the above mentioned step scan range were due to the following: the (111) reflection of the metastable tetragonal phase and the (11-1) and (111) reflections of the stable monoclinic phase. The resolution of these three reflections was poor: even for well crystallized materials (samples calcined at high temperatures), the two reflections of monoclinic zirconia were not completely resolved from that due to the metastable tetragonal phase. A pattern fitting technique based on the model developed by Schreiner and Jenkins [31] was therefore used to resolve the overlapping peaks. 
In this procedure, both the instrument- and the wavelength-related components of a powder diffraction profile are described by asymmetric Lorentzians. To carry out the fits, a Marquardt non-linear least squares algorithm was used [32].

The volume fraction $\left(V_{\mathrm{m}}\right)$ of the monoclinic zirconia phase in the calcined samples was calculated from the integrated intensity ratio $X_{\mathrm{m}}$ (eqn. 1):

$$
X_{\mathrm{m}}=\frac{I_{\mathrm{m}}(11-1)+I_{\mathrm{m}}(111)}{I_{\mathrm{m}}(11-1)+I_{\mathrm{m}}(111)+I_{\mathrm{t}}(111)}
$$

using the non-linear relationship (eqn. 2) proposed by Toraya et al. [33]:

$$
V_{\mathrm{m}}=\frac{P X_{\mathrm{m}}}{1+(P-1) X_{\mathrm{m}}}
$$

The constant $P$ of eqn. (2) was assumed to have the value 1.311 , as found experimentally by Toraya et al.; the same value was also found by Schmid [34]. A value for $P$ of $1.35 \pm 0.019$ has been calculated theoretically [33-35].

The crystallite sizes $\left(D_{\mathrm{hkl}}\right)$ of the various samples were calculated from the pattern-resolved peaks for the (11-1) and (111) reflections of the monoclinic phase and for the (111) reflection of the metastable tetragonal phase by using the Scherrer relationship (eqn. 3 ):

$$
D_{\mathrm{hkl}}=\frac{0.9 \lambda}{B_{\mathrm{hkl}} \cdot \cos \theta}
$$

$B_{\text {hkl }}$, the width of the peak at half the peak maximum corrected for both the effect of $K \alpha_{1}-K \alpha_{2}$ separation and instrumental broadening, was obtained directly from the pattern-fitting procedure applied; as a consequence, the instrumental broadening is accounted for assuming a Cauchy relationship [36].

\section{RESULTS}

\section{Chemical analysis}

$\mathrm{XRF}$ analysis of the uncalcined zirconia sample revealed the presence of the following impurities: $\mathrm{Hf}$ (major impurity), traces of $\mathrm{Cu}, \mathrm{Fe}, \mathrm{Ti}, \mathrm{K}$ and $\mathrm{Si}$, together with some $\mathrm{Cl}$. The bulk chloride analysis showed that this sample (hereafter termed standard batch of zirconia) contained less than $50 \mathrm{ppm}$ of chloride ions.

\section{Thermal analysis}

Typical TG and DSC results of the decomposition behaviour of the precipitate are shown in Figs. 1a and b, respectively. The TG weight loss curve is 

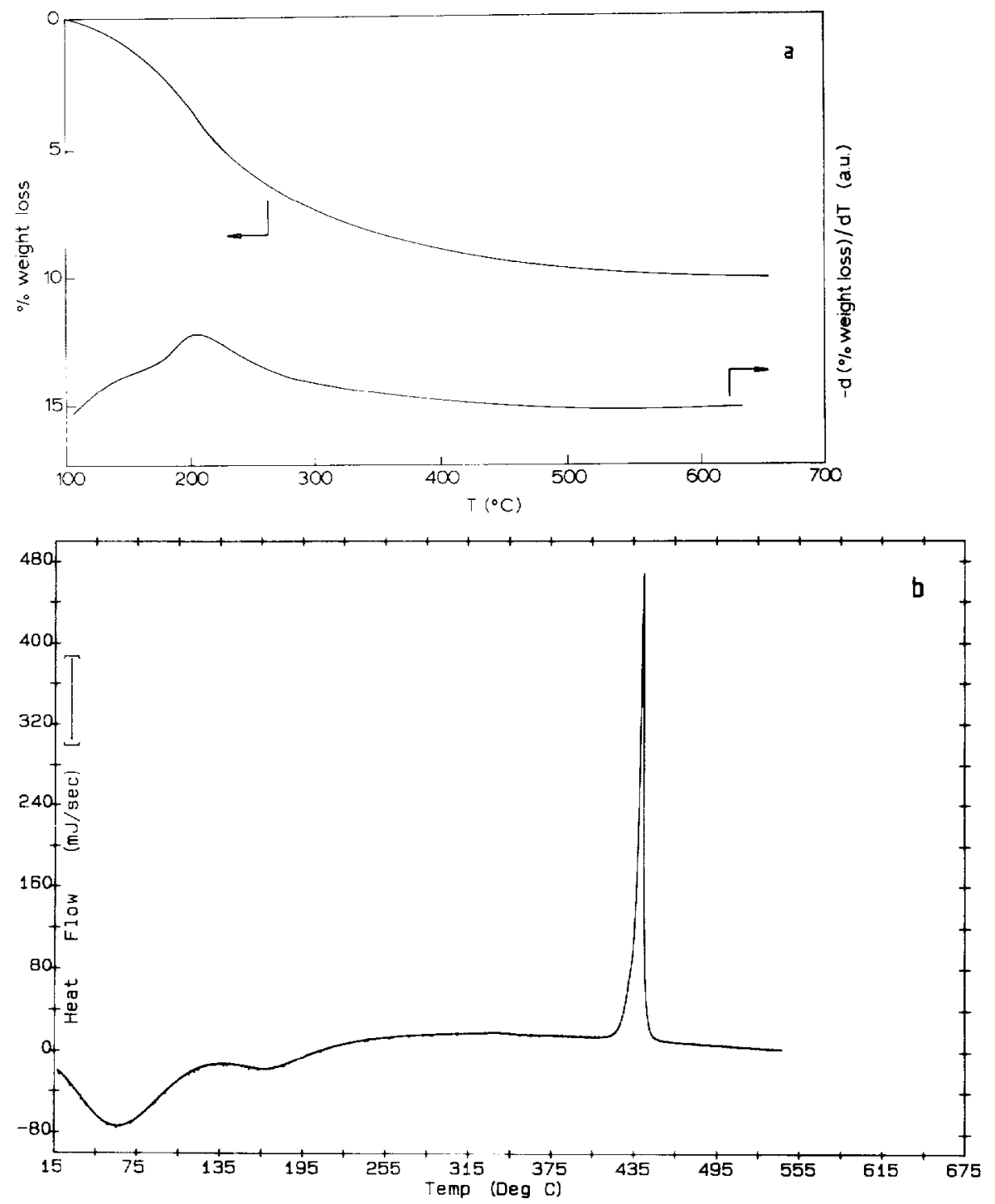

Fig. 1. Thermal analysis results on hydrous zirconia: (a) typical TG and corresponding DTG curves; (b) typical DSC curve.

typical of that found with a gel $[12,13,37,38]$, dehydration occurring continuously over the whole range of temperature studied. The final weight loss is about $10 \%$ of the initial sample weight; this result is in good agreement with the findings of other investigators for similar $\mathrm{ZrO}_{2}$ systems.

The DSC curve is also typical and shows two distinct endotherms at about 60 and $165^{\circ} \mathrm{C}$, corresponding to the volatilization of physically adsorbed and crystalline water respectively; the first peak was not visible in the TG results 
as the sample studied there had been dried at $100^{\circ} \mathrm{C}$. At about $443^{\circ} \mathrm{C}$, an intense and very sharp exothermic peak is observed. The heat effect associated with this so called 'glow exotherm' is estimated to be $19.6 \mathrm{~kJ}\left(\mathrm{~mol} \mathrm{ZrO}_{2}\right)^{-1}$.

\section{Phase composition and line broadening analysis}

The X-ray diffractogram of the uncalcined sample showed only two very broad bands in the range of 20 from 18 to $40^{\circ}$ and from 40 to $70^{\circ}$, this being indicative of a very low degree of crystallinity. The diffractogram of the samples calcined at $450^{\circ} \mathrm{C}$ and higher showed that these consisted of mixtures of the stable monoclinic phase and a metastable phase which could be either tetragonal or cubic. The XRD patterns of the cubic and the tetragonal zirconia modifications are nearly identical; the only difference is that the tetragonal phase shows a limited number of additional high order, low intensity reflections due to its lower degree of symmetry. Because of the broadness of the XRD peaks exhibited by the calcined samples studied in this work, it is therefore not possible to establish clearly from the X-ray results whether the metastable zirconia phase formed is tetragonal or cubic.

The tetragonal and cubic phases may however be readily identified and distinguished from one another by means of Raman spectroscopy. On the basis of both factor-group analysis [39,40] and experimental results [38,40,41] (supplemented by Raman work from our own laboratory), tetragonal zirconia is expected to yield a spectrum consisting of six Raman bands (with frequencies at about 148, 263,325, 472,608 and $640 \mathrm{~cm}^{-1}$ ) while cubic zirconia is expected to yield a single Raman band centered around $490 \mathrm{~cm}^{-1}$. A typical Raman spectrum of a sample of zirconia calcined at $450^{\circ} \mathrm{C}$ is shown in Fig. 2; for comparison purposes, Raman spectra of two monoclinic zirconia samples are also given. The absence of a band at $490 \mathrm{~cm}^{-1}$ and the presence of the five strongest bands (marked with triangles) for tetragonal zirconia indicate that the standard batch of hydrous zirconia crystallizes into the tetragonal phase rather than into the cubic phase. Further, by comparison with the spectra for monoclinic zirconia, it can be seen that a small proportion of this phase is also present in the sample calcined at $450^{\circ} \mathrm{C}$. In addition, there is also some evidence from the $\mathrm{X}$-ray diffractogram that the crystallization process is not complete at $450^{\circ} \mathrm{C}$ : deconvolution results in a tetragonal peak superimposed on a very broad band. Nevertheless, it is estimated that more than $70 \%$ of the volume of sample responsible for the diffraction pattern is metastable tetragonal zirconia $\left(\mathrm{V}_{\mathrm{m}}<0.3\right)$.

The volume fraction $\left(V_{\mathrm{m}}\right)$ of monoclinic phase and the crystallite sizes $\left(D_{\mathrm{hkl}}\right)$ of the monoclinic and tetragonal phases calculated from the XRD results are plotted in Figs. 3a and b respectively as a function of calcination temperature. (Before using the integrated intensity data for the calculation of $V_{m}$, the data for monoclinic zirconia were checked for a possible effect of preferred orien- 


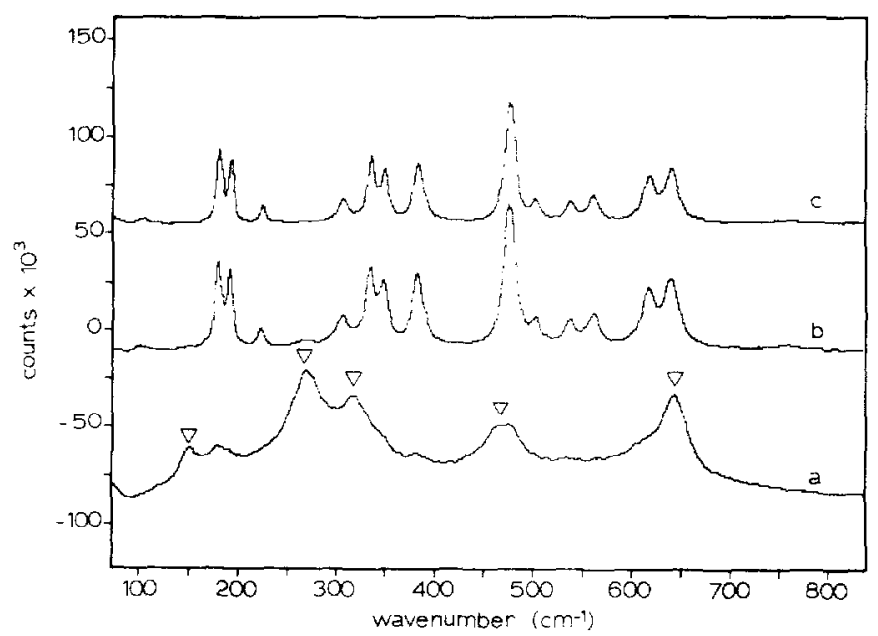

Fig. 2. Typical Raman spectra of different $\mathrm{ZrO}_{2}$ samples: (a) a predominantly 'metastable' tetragonal sample obtained by calcining hydrous zirconia at $450^{\circ} \mathrm{C}$ (triangles indicate strongest bands resulting from the 'metastable' tetragonal phase); (b) a predominantly monoclinic sample obtained by calcining hydrous zirconia at $850^{\circ} \mathrm{C}$; and (c) a $100 \%$ monoclinic sample (CERAC Chemicals, spectro grade monoclinic $\mathrm{ZrO}_{2}$ ).
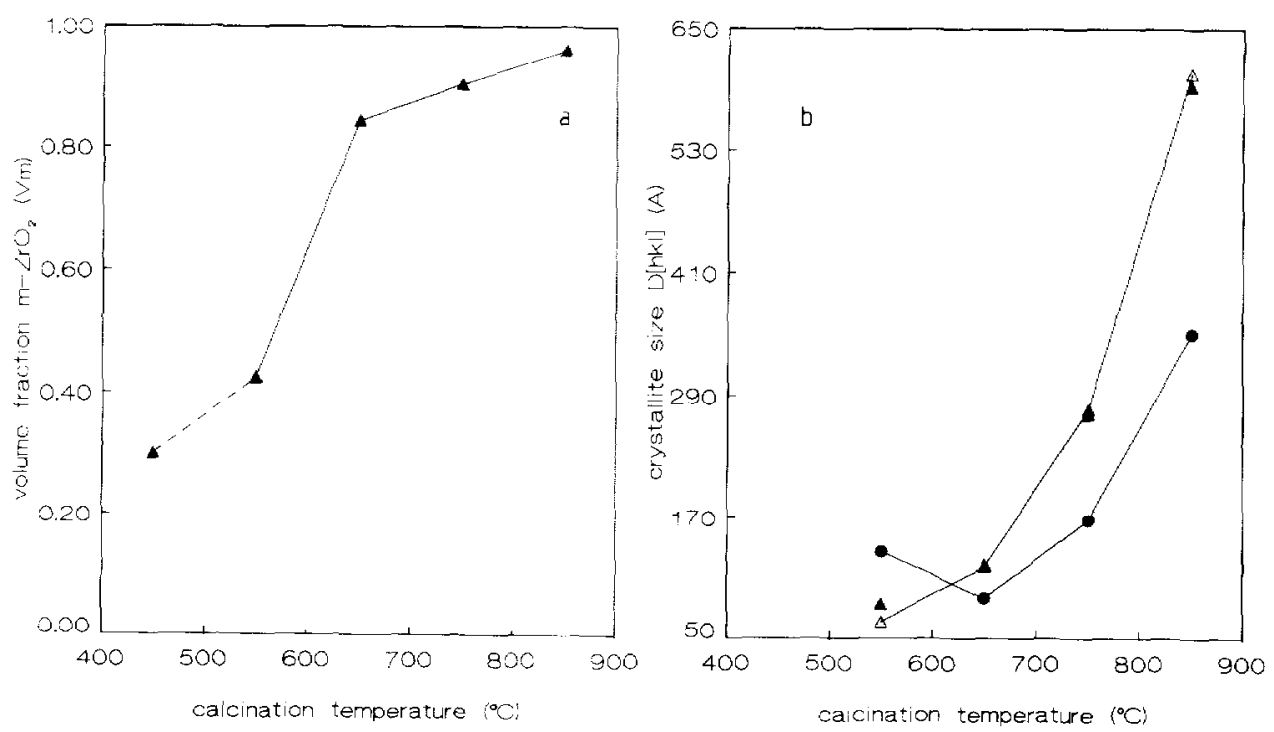

Fiy, 3. X-ray analysis results on hydrous zirconia: (a) effect of calcination temperature on the development of the volume fraction monoclinic $\mathrm{ZrO}_{2}$; (b) effect of calcination temperature on the development of the average crystallite size: - size calculated using the (111) reflection of the 'metastable' tetragonal phase; $\Delta$, size calculated using the (11-1) reflection of the monoclinic phase; and $\boldsymbol{\Lambda}$, size calculated using the (111) reflection of the monoclinic phase. 
tation. This possibility was ruled out by the observation of a reasonably constant ratio $I_{\mathrm{m}}(111) / I_{\mathrm{m}}(11-1)$ of about 0.74 for all calcination temperatures.) As can be seen from the plot of $V_{\mathrm{m}}$ vs. calcination temperature, the 'stability' of the metastable tetragonal phase is not great: the degree of transformation to the thermodynamically stable monoclinic phase increases steadily with increase in calcination temperature. The crystallite size of the monoclinic phase also increases with increase in calcination temperature. Further, there is a good agreement between the sizes calculated from the (11-1) and (111) reflections; this result suggests that the monoclinic crystallites are isometric in shape.

The crystallite size of the metastable tetragonal phase behaves in a rather less regular manner (Fig. 3b); it first appears to decrease (from 136.4 $\AA$ to 90.3 $\AA$ ) and then to increase again. A possible explanation for this phenomenon will be discussed in the next section. At the lowest calcination temperature, the monoclinic crystallites are smaller than the metastable tetragonal crystallites but the situation is reversed at higher calcination temperatures. It is also evident from Fig. $3 \mathrm{~b}$ that the monoclinic crystallites grow more rapidly than those of the tetragonal phase as the calcination temperature is increased.

\section{Physical adsorption measurements}

Full nitrogen adsorption/desorption isotherms were measured for the standard batch of zirconia, both before calcination and after calcination at 450 ,
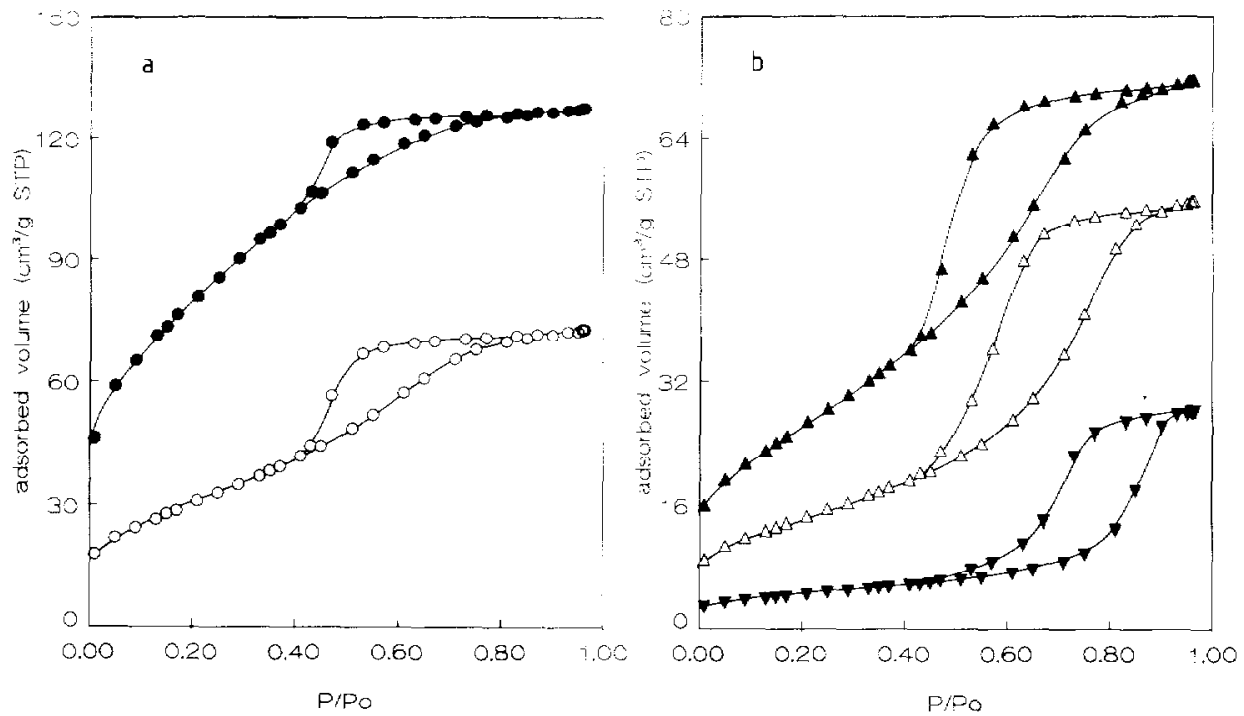

Fig. 4. Representative nitrogen adsorption/desorption isotherms at $-196^{\circ} \mathrm{C}$ on zirconia samples dried/calcined at different temperatures. (a): $O$, dried at $110^{\circ} \mathrm{C}$; and $\mathrm{O}$, calcined at $450^{\circ} \mathrm{C}$. (b): $\Delta$, calcined at $550^{\circ} \mathrm{C} ; \Delta$, calcined at $650^{\circ} \mathrm{C}$; and $\nabla$, calcined at $750^{\circ} \mathrm{C}$. 
$550,650,750$ and $850^{\circ} \mathrm{C}$. Representative isotherms are shown in Figs. $4 \mathrm{a}$ and b. All the isotherms were of type IV (BDDT classification [43,44]), being characteristic of well-developed mesoporous systems (pore widths between 20 and $500 \AA[44]$ ). The shape of the hysteresis loop changed gradually from that of type $E$ to type $A$ (following the classification of De Boer [45]) with increasing calcination temperature. (Note that in the recently published IUPAC classification [44], types $\mathrm{A}$ and $\mathrm{E}$ are denoted as $\mathrm{H} 1$ and $\mathrm{H} 2$ respectively).

Table 1 lists the most important textural parameters calculated from the isotherm for each temperature. The values of the specific surface area $\left(S_{\mathrm{BET}}\right)$ were calculated using a value of $0.162 \mathrm{~nm}^{2}$ for the cross-sectional area of the nitrogen molecule $[43,44]$ and the values of the total pore volume $\left(V_{p}\right)$ were calculated from the plateaus of the corresponding adsorption isotherms [43]. Table 1 also lists the values of the specific surface area $\left(S_{t}\right)$ calculated using the t-plot method [46]; $S_{\mathrm{t}}$ represents the sum of the areas of the mesopore walls and the external surface. Examples of the plots of the adsorbed volume vs. the statistical thickness $t$ used in these calculations are shown in Figs. 5a and $b$. The $t$-plots were calculated by the $n$-method of Lecloux $[30,47]$; in the selection of the standard isotherm, this method takes into account the $C_{\mathrm{BET}}$ value and consequently the adsorbate-adsorbent interaction. The numerical value for $S_{\mathrm{t}}$ at each calcination temperature was calculated from the slope of the linear branch of the respective t-plot using eqn. (4):

$S_{\mathrm{t}}=15.47\left\{\delta V_{\text {ads }} / \delta \mathrm{t}\right\}$

In those cases for which the t-plot indicated the presence of microporosity (pore widths $<20 \AA[44]$ ), the micropore volume $\left(V_{\text {micro }}\right)$ was also estimated. (Microporosity is indicated by a positive intercept on the adsorbed volumeaxis of the extrapolated linear branch of the t-plot [43,48].) From the intercepts and taking the appropriate density for liquid nitrogen [43], the numerical values for $V_{\text {micro }}$ were calculated; these are listed in the last column of Table

\section{TABLE 1}

Effect of the calcination temperature on the specific surface area and porosity of standard zirconia samples

\begin{tabular}{lllllrl}
\hline $\begin{array}{l}\text { Calcination } \\
\text { temperature } \\
\left({ }^{\circ} \mathrm{C}\right)\end{array}$ & $\begin{array}{l}\text { Isotherm } \\
\text { type }\end{array}$ & $\begin{array}{l}\text { Hysteresis } \\
\text { type }\end{array}$ & $\begin{array}{l}S_{\mathrm{BET}} \\
\left(\mathrm{m}^{2} / \mathrm{g}\right)\end{array}$ & $\begin{array}{l}V_{\mathrm{p}} \\
\left(\mathrm{cm}^{3} / \mathrm{g}\right)\end{array}$ & $\begin{array}{l}S_{\mathrm{t}} \\
\left(\mathrm{m}^{2} / \mathrm{g}\right)\end{array}$ & $\begin{array}{l}V_{\text {micro }} \\
\left(\mathrm{cm}^{3} / \mathrm{g}\right)\end{array}$ \\
\hline 110 & IV & $\mathrm{E}$ & 289.1 & 0.195 & 215.9 & 0.033 \\
450 & IV & $\mathrm{E}$ & 111.1 & 0.112 & 88.6 & 0.010 \\
550 & IV & $\mathrm{E}$ & 96.9 & 0.111 & 74.2 & 0.009 \\
650 & IV & $\mathrm{A} / \mathrm{E}$ & 52.7 & 0.086 & 45.2 & 0.004 \\
750 & IV & $\mathrm{A}$ & 15.8 & 0.043 & 16.1 & 0.000 \\
850 & IV & $\mathrm{A}$ & 2.9 & 0.010 & 3.0 & 0.000 \\
\hline
\end{tabular}



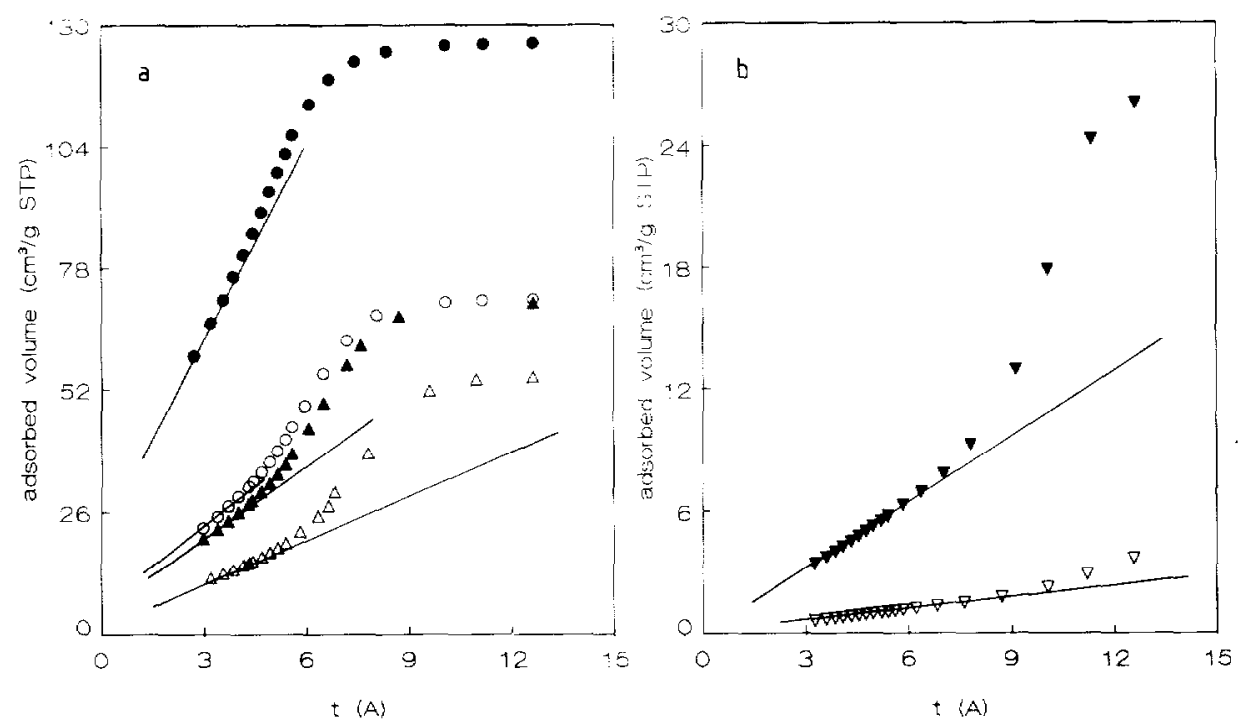

Fig, 5. Representative $V_{\mathrm{ads}}-t$ plots obtained from analysis of the nitrogen adsorption data for zirconia dried/calcined at various temperatures. (a): $\bullet$, dried at $110^{\circ} \mathrm{C} ; \mathrm{O}$, calcined at $450^{\circ} \mathrm{C}$; $\Delta$, calcined at $550^{\circ} \mathrm{C}$; and $\triangle$, calcined at $650^{\circ} \mathrm{C}$. (b): $\nabla$, calcined at $750^{\circ} \mathrm{C}$; and $\nabla$, calcined at $850^{\circ} \mathrm{C}$.

1. From the results summarized in Table 1 , it is evident that the porous texture of the zirconia samples prepared is not stable, the initially high specific surface area and total specific pore volume decreasing markedly on increasing the calcination temperature.

The mesopore size distribution for each sample was calculated following the method developed by Barrett, Joyner and Halenda (the BJH method) assuming a cylindrical pore model [49]. The calculations were applied to the adsorption branch of the isotherms which, according to Broekhoff [29], is the stable branch when hysteresis loops of the type observed are involved. The equation of Halsey [50] (fitted to the standard isotherm for $100<C_{\mathrm{BET}}<300$ given by Lecloux and Pirard [47]) was used for multilayer thickness corrections. The calculated cumulative specific surface areas $\left(S_{\text {cum }}\right)$ and pore volumes $\left(V_{\text {cum }}\right)$, as well as the most frequent pore radii $\left(R_{\mathrm{p}}(\max )\right)$, are listed in Table 2 . The corresponding pore size distributions are shown in Figs. 6a and b. From the two figures it is evident that all the samples (with the exception of the uncalcined material) exhibited unimodal pore size distributions. (The pore size distribution for the uncalcined sample has no maximum in the pore size range down to approximately $15 \AA$, the lower limit to the practical use of the Kelvin equation $[29,43]$.) On calcination at increasing temperatures, the pore size distributions, and consequently also $R_{\mathrm{p}}(\max )$, are seen to shift towards higher values. 
TABLE 2

BJH analysis results $\left(V_{\text {cum }}, S_{\text {cum }}\right.$ and $\left.R_{\mathrm{p}}(\max )\right)$ as a function of calcination temperature

\begin{tabular}{llll}
$\begin{array}{l}\text { Calcination } \\
\text { temperature } \\
\left({ }^{\circ} \mathrm{C}\right)\end{array}$ & $\begin{array}{l}V_{\text {cum }} \\
\left(\mathrm{cm}^{3} / \mathrm{g}\right)\end{array}$ & $\begin{array}{l}S_{\text {cum }} \\
\left(\mathrm{m}^{2} / \mathrm{g}\right)\end{array}$ & $\begin{array}{l}R_{\mathrm{p}}(\max ) \\
(\mathrm{A})\end{array}$ \\
\hline 110 & 0.065 & 62 & - \\
450 & 0.072 & 61 & 15.8 \\
550 & 0.080 & 62 & 20.4 \\
650 & 0.075 & 45 & 35.9 \\
750 & 0.041 & 14 & 72.2 \\
850 & 0.010 & 2 & 102.9 \\
\hline
\end{tabular}

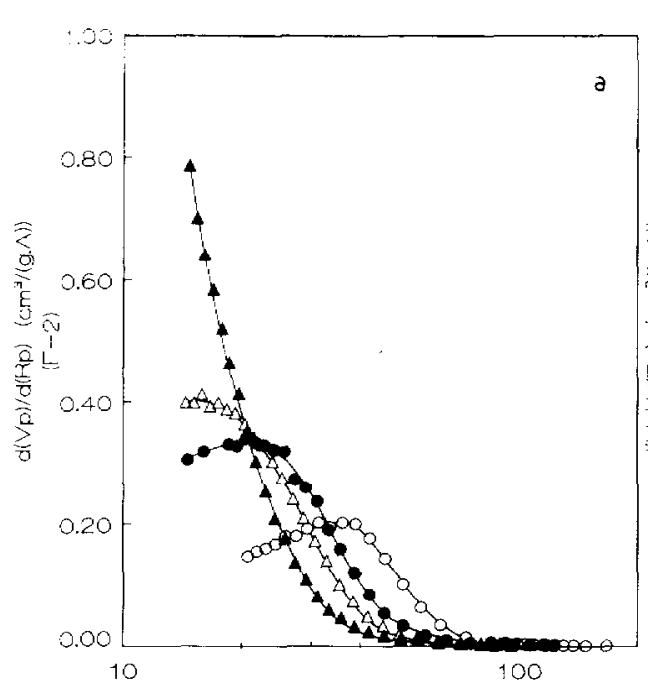

$\operatorname{Rp}\{A\}$

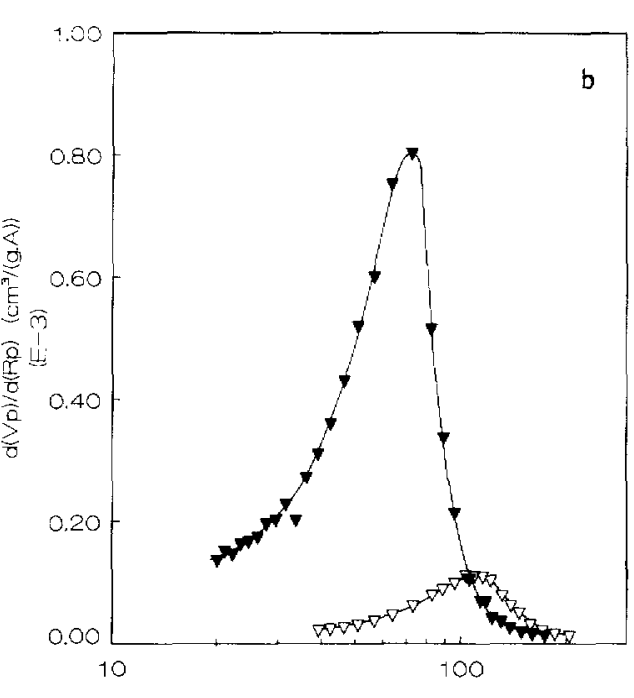

Rio (A)

Fig. 6. Effect of calcination temperature on the development of the mesopore size distribution of hydrous zirconia. (a): $\Delta, 110^{\circ} \mathrm{C} ; \triangle, 450^{\circ} \mathrm{C} ;-550^{\circ} \mathrm{C}$; and $\mathrm{O}, 650^{\circ} \mathrm{C} .(\mathrm{b}): \nabla, 750^{\circ} \mathrm{C}$; and $\nabla$ $850=\mathrm{C}$.

\section{DISCUSSION}

\section{DSC behaviour and crystallization of hydrous zirconia}

The DSC behaviour reported here (Fig. 1b) is typical of that for zirconia prepared via wet-chemical routes. The glow-exotherm obtained at about $443^{\circ} \mathrm{C}$ is similar to the exotherms reported by, for example, Srinivasan et al. [38] (exotherm at about $450^{\circ} \mathrm{C}$ ), Torralvo et al. [51] (exotherm in the range 420$440^{\circ} \mathrm{C}$ ), Livage et al. [52] (exotherm at about $430^{\circ} \mathrm{C}$ ), and Gimblett et al. 
[53] (exotherm at about $470^{\circ} \mathrm{C}$ ). Gimblett et al. showed further that the exact temperature of the glow-exotherm is dependent on the preparation conditions and on the environment used during a particular thermal analysis run. The enthalpy change associated with the exotherm of Fig. $1 \mathrm{~b}\left(19.6 \mathrm{~kJ} \mathrm{~mol}^{-1}\right)$ is in good agreement with the values reported by Srinivasan et al. $\left(23.2 \mathrm{~kJ} \mathrm{~mol}^{-1}\right)$ and Torralvo et al. (16-19 $\left.\mathrm{kJ} \mathrm{mol}^{-1}\right)$. It is however smaller than the values reported by Livage et al. (29-34 $\mathrm{kJ} \mathrm{mol}^{-1}$ ) and by Haberko et al. [54] (28 kJ $\mathrm{mol}^{-1}$ ).

The existence of such a glow exotherm is not confined to zirconia, it being a well-documented feature of many metal oxide and hydrous oxide systems (see ref. 53 and references quoted therein). However, a satisfactory interpretation of its origin is still lacking. The occurrence of the glow phenomenon in hydrous zirconia systems is commonly associated with the transition of an initially $\mathrm{X}$ ray amorphous phase into a crystalline modification of zirconia. Our XRD and Raman spectroscopy results on the structure of the material as a function of calcination temperature indicate that the glow exotherm is probably associated with crystallization into the tetragonal modification. This interpretation is in agreement with the conclusions of Rijnten [12] and of Gimblett et al. [53]. On the other hand, Yuranova et al. [55] and Kommissarova et al. [56] attributed the exothermic effect to the crystallization of monoclinic $\mathrm{ZrO}_{2}$. Srinivasan et al. [38] have more recently reported DSC results showing that neither the peak temperature for the exotherm nor the heat effect involved was dependent on the nature of the crystal phase formed on crystallization. However, they probably did not consider the possibility that water could influence both the position and magnitude of their exotherms; Gimblett et al. [53] have shown that not only the peak position but also the magnitude of the glow-exotherm is sensitive to the extent of hydration/dehydration of the zirconia precursor. This observation probably also explains the scatter in the published numerical values for the peak temperature and the enthalpy effect.

\section{Tetragonal to monoclinic phase transformation and crystallite growth}

The zirconia samples prepared in this study all crystallized on calcination into the tetragonal phase rather than into the thermodynamically more stable monoclinic phase. The formation and 'stability' of the metastable tetragonal phase has previously been rationalized in different ways. On the basis of thermodynamic considerations, Garvie and coworkers $[23,57,58]$ and Pyun et al. [25] attributed the stabilization to surface- and strain energy effects; these effects allowed the calculation of a critical crystallite size below which the tetragonal phase was more stable than the monoclinic modification (vide infra). Rijnten [12] and also Mitsuhashi et al. [59] rationalized the stabilization in terms of a strain energy effect generated at domain boundaries. Livage et al. [52] considered the initial formation of the tetragonal phase to be a conse- 
quence of the structural similarity between the amorphous and tetragonal forms of $\mathrm{ZrO}_{2}$; this explanation is thus kinetic rather than thermodynamic. Similarly, Tani et al. [22] proposed a mechanism of topotactic crystallization of tetragonal zirconia on nuclei in the amorphous $\mathrm{ZrO}_{2}$. In yet another approach, Davis [60] argued that the tetragonal phase is stabilized by chemical factors introduced during the precipitation process (e.g. by the $\mathrm{pH}$ ). Finally, Soria and coworkers [21,51] advanced the idea that non-stoichiometry serves to initiate the transformation. The non-stoichiometry effect can probably be excluded for our zirconia samples as all those studied were white; non-stoichiometric zirconia is known to be gray or black $[21,51,52]$. The kinetic explanations offered by Livage et al. and by Tani et al. cannot be considered because of lack of experimental evidence in the present study. We shall now discuss the critical size and the strain energy theories which, from a thermodynamical point of view, are complementary.

Using published experimental data, Garvie and Goss [57] and Garvie [58] calculated that tetragonal crystallites greater than approximately $100 \AA$ cannot exist at room temperature. This calculation required the existence of unconstrained single crystals. Garvie argued further that polycrystallinity and strain (as a consequence of hydrostatic and/or non-hydrostatic stresses) would result in an increase of the critical crystallite size at room temperature. Interpretation of these ideas result in the following sequence of events with increase of calcination temperature: (i) tetragonal zirconia sinters to form increasingly larger crystallites; (ii) a critical crystallite size is then reached; and (iii) a transformation from tetragonal to monoclinic crystallites occurs, the latter being larger than the tetragonal crystallites from which they are derived. (The density of the monoclinic modification is smaller than that of the tetragonal one, 5.56 as opposed to $6.10 \mathrm{~g} \mathrm{~cm}^{-3}$.) This sequence of physical processes has been observed qualitatively in this study when the calcination temperatures are above about $650^{\circ} \mathrm{C}$. A definite critical crystallite size cannot, however, be given. Further, it is most likely that kinetic factors have an influence on the stabilization and overall transformation process, determining both the temperature and rate of transformation and consequently also the apparent critical crystallite size; in every case, the transformation must be nucleated, a process which can be of considerable influence in view of the small crystallites involved. The thermodynamic criterion is a necessary, but not in itself, a sufficient condition for the tetragonal to monoclinic phase transformation.

Calcination at $550^{\circ} \mathrm{C}$ results in monoclinic crystallites which are much smaller than the tetragonal ones with which they co-exist, an observation that in not in agreement with the hypothesis discussed above. This 'strange' result has been reported previously by other investigators $[24,42,62]$ and has been explained tentatively in terms of twinning and/or strain fracture. However, in view of the small dimension of the crystallites involved in this study, this explanation does not seem probable to us. At present we do not have a definite 
explanation for this phenomenon, although we think that kinetic factors are highly involved (vide infra).

The foregoing discussions also make it possible to give a tentative explanation for the apparently strange changes of the sizes of the tetragonal crystallites on calcination from 550 to $650^{\circ} \mathrm{C}$ shown in Fig. 3b. But first, a critical consideration of the physical meaning of the crystallite size as obtained from $\mathrm{X}$-ray line broadening analysis is necessary. The mean crystallite size $\left(D_{\mathrm{hkl}}\right)$ calculated using the Scherrer relationship is a volume-averaged crystallite size defined by [63]:

$D_{\mathrm{hkl}}=\sum f_{i}\left(d_{i}\right)^{4} / \sum f_{i}\left(d_{i}\right)^{3}$

where $f_{i}$ is the frequency of occurrence of crystallites of size $d_{i}$. The existence of a distribution in the crystallite sizes of zirconia powders prepared via wetchemical routes is not uncommon, the broadness of the distribution being dependent on the exact conditions employed during hydrolysis/precipitation and thermal treatment $[12,59]$. The XRD results obtained after calcination at $650^{\circ} \mathrm{C}$ suggest that the critical crystallite size is within the range of 90 to 123 $\AA$, a value in any case smaller than the crystallite size of the tetragonal phase after calcination at $550^{\circ} \mathrm{C}$. This observation, in its turn, implies that kinetic factors probably govern the transformation. Kinetic effects are usually accompanied by an 'activation energy'; in this particular case this will be an activation energy for the phase transformation. If it is assumed that in addition to kinetic factors (resulting in an activation energy for the phase transformation) the samples prepared here also exhibit a distribution in the tetragonal crystallite sizes, the observed behaviour can be understood: it is possible that because of the existence of an activation energy for transformation, not all of the potentially transformable tetragonal crystallites convert into the monoclinic phase after calcination at $550^{\circ} \mathrm{C}$. This will result in a tetragonal crystallite size distribution of a volume-averaged size which is larger than it should be; this situation is depicted schematically in Fig. 7a for a tetragonal crystallite size distribution of an apparent volume-averaged size of $127 \AA$. Calcination at a higher temperature, $650^{\circ} \mathrm{C}$ in this particular case, is likely to bring about at least part of the transformation. The remaining tetragonal crystallites are all smaller than the critical crystallite size and so the new volume-averaged size is not only smaller than that of the monoclinic crystallites formed but, depending on the broadness of the distribution and more important on the actual value of the apparent critical size, possibly also much smaller than that at lower calcination temperature; this situation is depicted schematically in Fig. 7b.

\section{Development of the porous texture of zirconia on calcination}

All the nitrogen physisorption isotherms of Fig. $4 \mathrm{a}$ and $\mathrm{b}$ are well-developed type IV isotherms of the BDDT classification. The adsorbed volume vs. $t$ plots 

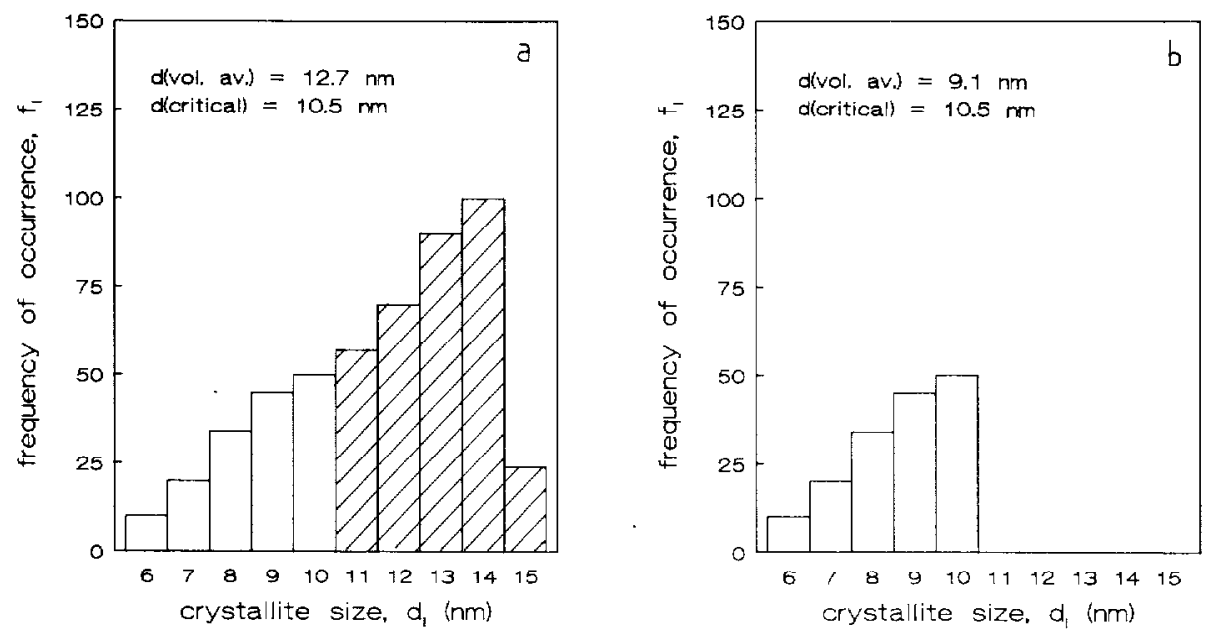

Fig. 7. Schematic crystallite size distributions of tetragonal zirconia. (a): sample calcined at a relatively low temperature e.g. $550^{\circ} \mathrm{C}$; the shaded area represents the crystallites which should have been transformed at this particular temperature but because of kinetic effects have not. (b): sample calcined at a higher temperature e.g. $650^{\circ} \mathrm{C}$; all the potentially transformable crystallites are converted yielding a distribution of a new volume-averaged size which is much smaller than that at the lower calcination temperature, 9.1 as opposed to $12.7 \mathrm{~nm}$.

of Figs. 5a and $b$ all show an upward deviation from the linear branch of the $t-$ plot with ascending $t$-values. The shape of the hysteresis loops in the isotherms of Figs. $4 a$ and $b$ changes from type $E$ to type $A$. An upward deviation from the linear part of the t-plot is indicative of capillary condensation in pores with curved surfaces [29,30]. E-type hysteresis is often associated with 'ink-bottle' pores, spheroidal cavities or voids between close-packed spherical particles $[30,45]$; on the other hand, A-type hysteresis is characteristic of cylindrical pores $[30,45]$.

The uncalcined sample, the sample calcined at 450 and $550^{\circ} \mathrm{C}$ and also, to some extent, the sample calcined at $650^{\circ} \mathrm{C}$, all contain micropores. The sample calcined at 750 and $850^{\circ} \mathrm{C}$ on the other hand, are free of micropores. These observations are consistent with the observation (Table 1) that the specific BET surface area of the uncalcined sample and of the samples calcined at or below $650^{\circ} \mathrm{C}$ are significantly larger than the corresponding values of $S_{t}$, the sum of the areas of the mesopore walls and the external surface; it is generally accepted that the presence of micropores leads to an over-estimation of the monolayer capacity and consequently to $S_{\mathrm{BET}}$-values which are unrealistically high $[43,61]$. The samples calcined at 750 and $850^{\circ} \mathrm{C}$, having no micropores, have $S_{\mathrm{BET}}$-values which are very close to the calculated $S_{\mathrm{t}}$-values. Our results also show that the values calculated for the cumulative specific surface areas $\left(S_{\text {cum }}\right)$ are much lower than the estimated values for $S_{\mathrm{t}}$ for calcination temperatures at or below $650^{\circ} \mathrm{C}$ (see table 1 and 2); the same discrepancy is found 
between the values of the cumulative pore volumes $\left(V_{\text {cum }}\right)$ and $\left(V_{\mathrm{p}}-V_{\text {micro }}\right)$. These differences are most certainly the result of the presence of narrow mesopores $\left(10 \leq R_{\mathrm{p}} \leq 15 \check{A}\right.$; see Figs. $6 \mathrm{a}$ and $\mathrm{b}$ ) which are not accounted for in the BJH-calculations performed and the somewhat unrealistic pore model assumed in these calculations.

The pore size distributions for the calcined samples (Figs. 6a and b) were all shown to be unimodal. The pore size distribution for the uncalcined sample showed no maximum in the pore size range down to approximately $15 \AA$. This result suggests that the uncalcined sample consists mainly of narrow mesopores and/or wide micropores, a suggestion supported by the short range of linearity found in the t-plot for this sample (see in this respect also ref. 43). Calcination at increasing temperatures causes the pore size distributions, and consequently also $R_{\mathrm{p}}(\max )$, to shift towards higher values.

The discussion of the preceeding paragraphs leads to the following model for the porous texture of zirconia: the freshly-prepared zirconia samples studied are essentially mesoporous and contain spherically-shaped pores which are gradually smoothed into cylindrically-shaped pores on calcination in air. (Note that this smoothing of the surface is also reflected in the shift of the point of first deviation from the linear branch of the t-plot towards higher $t$-values and consequently higher relative pressures with increasing calcination temperature.) At the same time, both the specific surface area and the total specific pore volume decrease markedly and these changes are accompanied by a progressive elimination of the micropores and a gradual widening of the pores. These changes in the pore structure and surface area are all consistent with the marked crystallite growth and accompanying phase transformation already discussed in the previous sub-section. Alternatively, these textural changes might be due to inter-crystallite sintering processes (neck formation and growth). In both cases, the mechanism operative would probably be surface diffusion, as the highest calcination temperature is well below the Tamman temperature of zirconia (ca. $1200^{\circ} \mathrm{C}$ ); moreover, the observation of widening of the pores is only compatible with a surface diffusional mechanism. An idea of which of the two processes (crystallite growth or inter-crystallite sintering) is dominant can be obtained by comparing the specific surface area accessible to nitrogen with the corresponding geometrical specific surface area calculated from the crystallite sizes.

The geometrical surface area can be calculated from the crystallite sizes determined by XRD line broadening analysis if it is assumed that: (i) tetragonal and monoclinic zirconia are separate phases, the appropriate weighting factor being the volume fraction $V_{\mathrm{m}}$; (ii) the respective crystallites have spherical geometry; and (iii) there are no closed pores. The calculated values for the geometrical specific surface area $\left(S_{\text {geo }}\right)$ are listed in Table 3. This table also gives the (relative) retention of this value $\left(\left[S_{\text {gen }}(T) / S_{\text {gen }}(550)\right]\right)$ on calcination at temperature $T$ and the fraction of the geometrical specific surface area 
which is not accessible $\left.\left(\left[S_{\text {geo }}-S_{\mathrm{BET}}\right) / S_{\text {geo }}\right]\right)$. Using geometric sintering models involving surface diffusion, it is possible to relate the latter value to a parameter $S_{\text {neck }} / S_{\text {geo }}$; this parameter represents the fraction (per interparticle contact) of the geometrical specific surface area which is neck area (see Fig. 8).

The fraction $\left[\left(S_{\mathrm{geo}}-\mathrm{S}_{\mathrm{BET}}\right) / S_{\mathrm{geo}}\right]$ is also significantly dependent upon the actual number of necks, i.e. upon the actual interparticle coordination number $[65,66]$. The coordination number can be estimated from the powder porosity if monosized spheres are considered. Relevant for this discussion is the interparticle coordination number of our sample calcined at $550^{\circ} \mathrm{C}$. The porosity $(\epsilon)$ of this sample is calculated to be $40 \%\left(\epsilon=\rho V_{p} /\left(1+\rho V_{p}\right), \rho\right.$ being the theoretical density and $V_{\mathrm{p}}$ the specific pore volume). From the relationship between porosity and coordination number for (theoretical) packings of uniform spheres (see for example ref. 65), the coordination number is estimated to be between six and eight; an average coordination number near seven is frequently found for uncompacted powders. The relationship between $\left[\left(S_{\mathrm{geo}}-S_{\mathrm{BET}}\right) / S_{\mathrm{geo}}\right]$ and $\left(S_{\text {neck }} / S_{\text {geo }}\right)$, according to the surface-transport-controlled sintering model advanced by German and Munir [65], is given in Fig. 9 for coordination numbers of six, seven and eight. From this figure it is evident that for a given interparticle coordination number, $\left[\left(S_{\mathrm{geo}}-S_{\mathrm{BET}}\right) / S_{\mathrm{geo}}\right]$ is proportional to $S_{\text {neck }} / S_{\text {geo }}$.

In conclusion, the results given in Table 3 suggest that both crystallite growth and the accompanying phase transformation and inter-crystallite sintering have a marked influence on the specific surface area and pore structure. As the calcination temperature is increased, the influence of neck growth becomes more and more pronounced, the fraction of the geometrical area which is neck area increasing steadily with increase in calcination temperature.

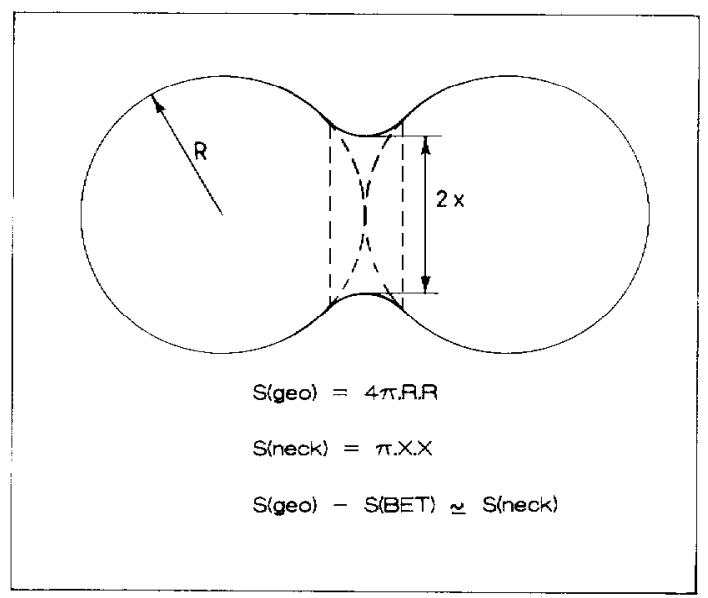

Fig. 8. Two-sphere model, illustrating geometric changes and relationships for a surface-transportcontrolled sintering process. 


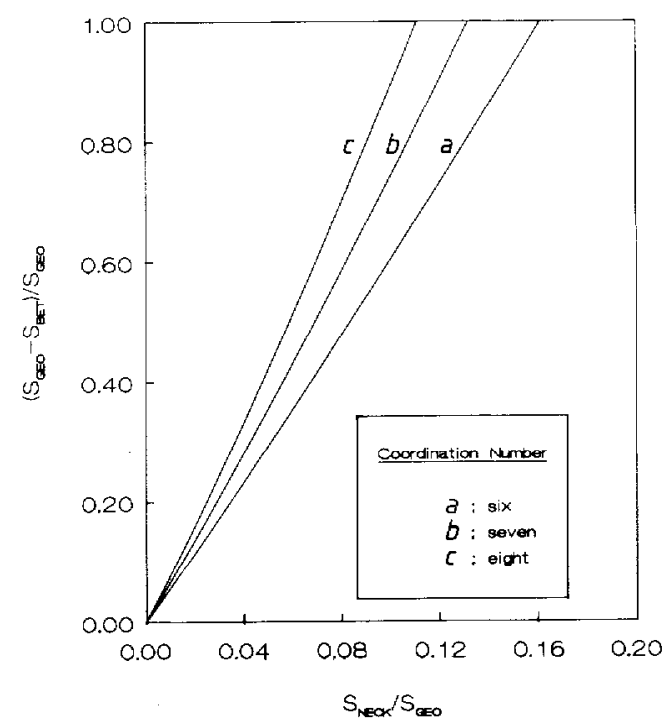

Fig. 9. The relationship between the fraction of the geometrical specific surface area which is not accessible ( $\left.\left.\left(S_{\mathrm{geo}}-S_{\mathrm{BET}}\right) / S_{\mathrm{geo}}\right]\right)$ and the fraction per contact of the geometrical surface area which is neck area $\left(S_{\text {neck }} / S_{\text {geo }}\right)$; the curves shown were calculated according to the geometrical sintering model advanced by German and Munir [65].

\section{TABLE 3}

Effect of calcination temperature on the extent of crystallite growth and sintering between the crystallites of zirconia, as reflected in the specific surface area

\begin{tabular}{llll}
\hline $\begin{array}{l}\text { Calcination } \\
\text { temperature } \\
\left({ }^{\circ} \mathrm{C}\right)\end{array}$ & $\begin{array}{l}S_{\mathrm{geo}} \\
\left(\mathrm{m}^{2} / \mathrm{g}\right)\end{array}$ & $S_{\mathrm{geo}}(T) / S_{\mathrm{geo}}(550)$ & $\left(S_{\mathrm{ger}}-S_{\mathrm{RET}}\right) / S_{\mathrm{geo}}$ \\
\hline 550 & 101 & 1 & \\
650 & 92 & 0.91 & 0.04 \\
750 & 41 & 0.41 & 0.43 \\
850 & 18 & 0.18 & 0.62 \\
\end{tabular}

In the considerations outlined above, we have assumed that $S_{\mathrm{BET}}$ is a measure of the accessible surface area. It should be noted however, as discussed in the preceeding paragraphs, that this is only strictly the case in the absence of microporosity. The samples calcined at $550^{\circ} \mathrm{C}$ and $650^{\circ} \mathrm{C}$ are to some extent microporous. The value of $S_{\mathrm{BET}}$ for these samples is therefore an over-estimate of the accessible surface area and so the corresponding values of $\left(S_{\mathrm{geu}}-S_{\mathrm{BET}}\right) /$ $S_{\text {geo }}$ of Table 3 only give a lower limit to the extent of neck growth.

(It should be noted that the pore textural changes which have been described in the preceeding paragraphs are typical of the 'intermediate sintering stage' 
as described in the classical sintering theories [67]. The intermediate sintering stage is arbitrary characterized by $S_{\text {neck }} / S_{\text {geo }}>0.023$. From Fig. 9 it can be inferred that the occurrence of the intermediate sintering stage is most probable if [ $\left.\left(S_{\mathrm{geo}}-S_{\mathrm{BET}}\right) / S_{\text {geo }}\right]$ is greater than approximately 0.18 . It can be consequently concluded from Table 3 , that the intermediate sintering stage is most likely for calcination temperatures in excess of $550^{\circ} \mathrm{C}$. In other words, the changes in pore texture described and discussed above are also all consistent with classical sintering theories, this lending extra probability to our interpretation of the results obtained.)

\section{CONCLUSIONS}

The reported data show that a high surface area zirconia with a well-developed mesoporous texture can be made by means of gel precipitation. The thermal stability of the prepared samples is however not satisfactorily, the initial high specific surface area being lost quite rapidly over the range of temperatures studied.

Two possible processes have been identified as being responsible for the changes occurring in the pore structure and surface area on calcination in air: crystallite growth and the accompanying phase transformation on the one hand and sintering between the crystallites (neck formation and growth) on the other. It has also been established that the monoclinic crystallites exhibit a more marked growth on calcination than do the tetragonal ones.

Critical comparison of the XRD-and physisorption data leads to the conclusion that crystallite growth and the accompanying phase transformation together with sintering between the crystallites (both probably by a surface diffusion mechanism) have an influence on the specific surface area and pore structure. The influence of inter-crystallite sintering becomes more and more pronounced at higher calcination temperatures. We shall show in a subsequent publication that these conclusions have allowed us to develop methods for obtaining texturally more stable zirconias.

\section{ACKNOWLEDGEMENTS}

We should like to thank $W$. Lengton for performing the wet-chemical analyses, H. Weber for his help with the XRF-measurements and J. Boeijsma for his assistance with the X-ray diffraction measurements. The help of J. Uiterwijk who carried out the computer programming work necessary for the use of the pattern-fitting technique described, is also gratefully acknowledged. 


\section{REFERENCES}

37 K.S. Mazdiyasni, in J.W. Mitchell, R.C. de Vries, R.W. Roberts and P. Cannon (Eds.), Reac-

tivity of Solids, Wiley Interscience, New York, 1969, p. 115.

B. Denisc and R.P.A. Sneeden, Appl. Catal., 28 (1986) 235.

Y. Amenomiya, Appl. Catal., 30 (1987) 57.

Y. Amenomiya, I.T. Ali Emesh, K.W. Oliver and G. Pleizier, in M.J. Phillips and M. Ternan (Eds.), Proc. 9th Int. Congr. Catal., Calgary, Vol. 2, 1988 p. 634.

T. Iizuka, Y. Tanaka and K. Tanabe, J. Catal., 76 (1982) 1.

T. Iizuka, Y. Tanaka and K. Tanabe, J. Mol. Catal., 17 (1982) 381.

T. Iizuka, M. Koijma and K. Tanabe, J. Chem. Soc., Chem. Commun., (1983) 638.

L.A. Bruce and J.F. Mathews, Appl. Catal., 4 (1982) 353.

L.A. Bruce, G.J. Hope and J.F. Mathews, Appl. Catal., 8 (1983) 349.

R.A. Dalla Betta, A.G. Piken and M. Shelef, J. Catal., 40 (1975) 173.

D.L. Trimm and A. Stanislaus, Appl. Catal., 21 (1986) 215.

D.L. Trimm, Design of Industrial Catalysts (Chemical Engineering Monographs 11), Elsevier, Amsterdam, 1980, p. 91.

H.Th. Rijnten, Thesis, Delft University of Technology, 1971.

E. Crucean and B. Rand, Trans. J. Brit. Ceram. Soc., 78 (1979) 58.

F.G.R. Gimblett, A.A. Rahman and K.S.W. Sing, J. Colloid Interface Sci., 84 (1981) 337.

F.G.R. Gimblett, A.A. Rahman and K.S.W. Sing, J. Colloid Interface Sci., 102 (1984) 483.

C. Otero Arean, M.A. Villa Garcia and J.M. Fernandez Collinas, Mater. Chem. Phys., 13 (1985) 163.

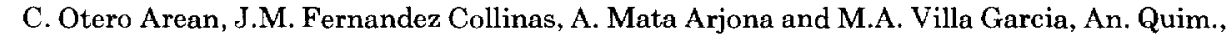
78 (1982) 146.

M.L. Veiga Blanco, M. Vallet Regi, A. Mata Arjona and E. Gutierrez Rios, An. Quim., 76 (1980) 346.

F.G.R. Gimblett, A. Hussain and K.S.W. Sing, J. Chem. Tech. Biotechnol., 41 (1988) 277.

F.G.R. Gimblett, A. Hussain and K.S.W. Sing, J. Colloid Interface Sci., 125 (1988) 619.

M.I. Osendi, J.S. Moya, C.J. Serna and J. Soria, J. Am. Ceram. Soc., 68 (1985) 135.

E. Tani, M. Yoshimura and S. Somiya, J. Am. Ceram. Soc., 66 (1983) 11.

R.C. Garvie, J. Phys. Chem., 69 (1965) 1238.

Y. Murase and E. Kato, J. Am. Ceram. Soc., 66 (1983) 196.

S-I. Pyun, H-J. Jung and G-D. Kim, in P. Vincenzini (Ed.), High Tech Ceramics, Elsevier, Amsterdam, 1987, p. 271.

M.A. Villa Garcia, M.C. Trobajo Fernandez and C. Otero Arean, Thermochim. Acta, 126 (1988) 33.

P. Turlier, J.A. Dalmon, G.A. Martin and P. Vergnon, Appl. Catal., 29 (1987) 305.

M.A.C.G. van de Graaf, J.H.H. ter Maat and A.J. Burggraaf, J. Mater. Sci., 20 (1985) 1407. J.C.P. Bruekhoff, in B. Delmon, P. Grange, P. Jacols and G. Poncelet (Eds.), Preparation of Catalysts II, Elsevier, Amsterdam, 1979, p. 663.

A.J. Lecloux, in J.R. Anderson and M. Boudart (Eds.), Catalysis (Sciene and Technology), Springer-Verlag, Berlin, 1981, p. 171.

W.N. Schreiner and R. Jenkins, Adv. X-ray Anal., 26 (1983) 141.

D.W. Marquardt, J. Soc. Ind. Appl. Math., 11 (1963) 431.

H. Toraya, M. Yoshimura and S. Somiya, J. Am. Ceram. Soc., 67 (1984) C-119.

H.K. Schmid, J. Am. Ceram. Soc., 70 (1987) 367.

P.A. Evans, R. Stevens and J.G.P. Binner, Brit. Ceram. Trans. J., 83 (1984) 39.

H.P. Klug and L.E. Alexander, X-Ray Diffraction Procedures, Wiley, New York, 1974, p. 635. 
R. Srinivasan, M.B. Harris, S.F. Simpson, R.J. De Angelis and B.H. Davis, J. Mater. Res., 3 (1988) 787.

39 W.B. White, Mater. Res. Bull., 2 (1967) 381.

40 V.G. Keramidas and W.B. White, J. Am. Ceram. Soc., 57 (1974) 22.

41 C.M. Philippi and K.S. Mazdiyasni, J. Am. Ceram. Soc., 54 (1971) 254.

42 R. Srinivasan, R. De Angelis and B.H. Davis, J. Mater. Res., 1 (1986) 583.

43 S.J. Gregg and K.S.W. Sing. Adsorption, Surface Area and Porosity, 2nd edn., Academic Press, London, 1982.

44 K.S.W. Sing, D.H. Everett, R.A.W. Haul, L. Moscou, R.A. Pierotti, J. Rouquerol and T. Siemieniewska, Pure \& Appl. Chem., 57 (1985) 603.

45 J.H. de Boer, in D.H. Everett and F.S. Stone (Eds.), The Structure and Properties of Porous Materials, Butterworths, London, 1958, p. 68.

46 B.C. Lippens and J.H. de Boer, J. Catal., 4 (1965) 319.

47 A. Lecloux and J.P. Pirard, J. Colloid Interface Sci., 70 (1979) 265.

48 K.S.W. Sing, Chem. Ind., (1967) 829.

49 E.P. Barrett, L.G. Joyner and P.P. Halenda, J. Am. Chem. Soc., 73 (1951) 373.

50 G. Halsey, J. Chem. Phys., 16 (1948) 931.

51 M.J. Torralvo, M.A. Alario and J. Soria, J. Catal., 86 (1984) 473.

52 J. Livage, K. Doi and C. Mazieres, J. Am. Ceram. Soc., 51 (1968) 349.

53 G. Gimblett, A.A. Rahman and K.S.W. Sing, J. Chem. Tech. Biotechnol., 30 (1980) 51.

54 K. Haberko, A. Ciesla and A. Pron, Ceram. Int., 1 (1975) 111.

55 L.T. Yuranova, L.N. Komissarova and V.E. Pluyshchev, Russ. J. Inorg. Chem. (English Trans.), 7 (1962) 546.

56 L.N. Komissarova, Y.P. Simanov and Z.A. Vladimirov, Russ. J. Inorg. Chem. (English Trans.), 5 (1960) 687.

57 R.C. Garvie and M.F. Goss, J. Mater. Sci., 21 (1986) 1253.

58 R.C. Garvie, J. Phys. Chem., 82 (1978) 218.

59 T. Mitsuhashi, M. Ichihara and U. Tatsuke, J. Am. Ceram. Soc., 57 (1974) 97.

60 B.H. Davis, J. Am. Ceram. Soc., 67 (1984) C-168.

61 F.A. Shebl, M. Abd El-Khalik and F.M. Helmy, Surf. Technol., 19 (1983) 321.

62 M.A. Blesa, A.J.G. Maroto, S.I. Passaggio, N.E. Figliolia and G. Rigotti, J. Mater. Sci., 20 (1985) 4601.

63 J.R. Anderson, Structure of Metallic Catalysts, Academic Press, New York, 1975, p. 365.

64 T. Ogihara, N. Mitzutani and M. Kato, Ceram. Int., 13 (1987) 35.

65 R.M. German and Z.A. Munir, Metall. Trans. B, 6B (1975) 289.

66 R.M. German and Z.A. Munir, in G.C. Kuczynski (Ed.), Materials Science Research, Vol. 10, Plenum Press, New York, 1975, p. 249.

67 R.L. Coble and J.E. Burke, in J.E. Burke (Ed.), Progress in Ccramic Science, Vol. 3, Pergamon, Oxford, 1963, p. 199. 